\title{
The study of the working body of the sowing complex in flowvision
}

\author{
Grigory Tatarov ${ }^{1, *}$, Vladimir Kurdumov ${ }^{1}$, and Ivan Sharonov ${ }^{1}$ \\ ${ }^{1}$ Ulyanovsk State Agrarian University named after Stolypin P. A.
}

\begin{abstract}
The studies performed clearly show the distribution of soil pressure on the working surface of the opener and allow a comparative assessment based on the experimental data obtained.
\end{abstract}

In the course of research, the angle of sharpening $\alpha$ of the stand of the proposed opener [1] ranged from $30^{\circ}$ to $50^{\circ}$, and the angle of inclination $\beta$ of the stand of the opener varied from $0^{\circ}$ to $10^{\circ}$. Search experiments revealed that when the grinding angle of the coulter stand developed by us is less than $30^{\circ}$, its weight increases significantly. Based on this, further studies of openers with smaller sharpening angles were not performed due to increased material intensity. With an increase in the speed of the seeder, exceeding the established agrotechnical requirements (more than $2.4 \mathrm{~m} / \mathrm{s}$ ), the density and height of the seeded soil layer decreases to values that do not meet agrotechnical requirements. In this regard, the studies performed in the program were modeled in accordance with the agrotechnical requirements.

The visualization of the movement of the coulters (Fig. 1,2) allows you to display the movement of soil particles along the working surface of the coulters, which clearly shows a decrease in soil pressure on the proposed coulter compared to the standard, and, therefore, traction resistance.
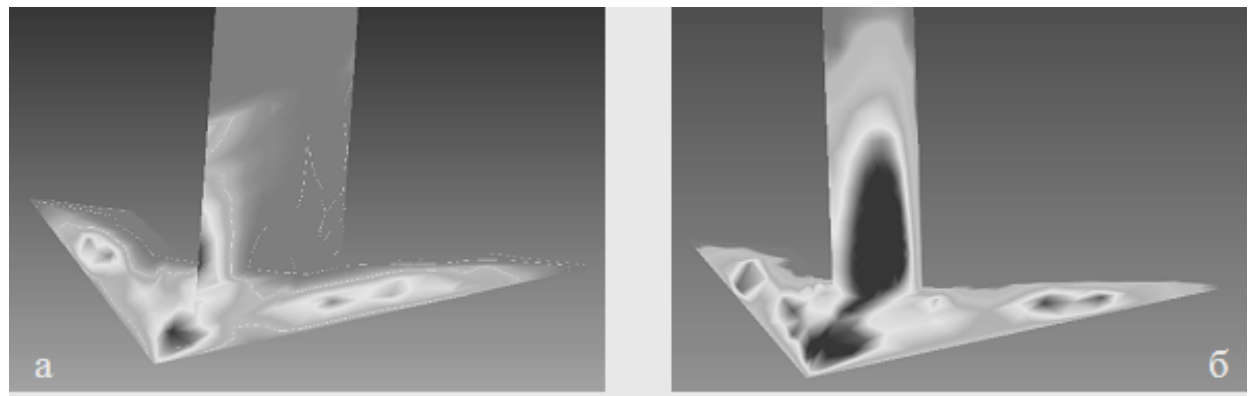

Fig. 1. Soil pressure on coulters: a - proposed; b - serial

\footnotetext{
*Corresponding author: tatarovgl@gmail.com
} 


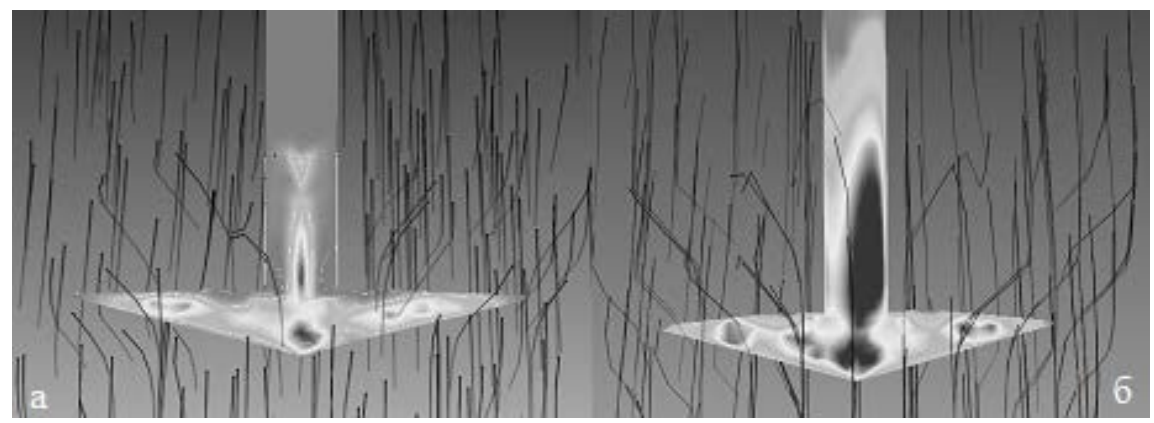

Fig. 2. Soil particles flow around the coulters: a - proposed; b - serial.

By performing the wedge-shaped coulter stand, the soil does not wrinkle before the coulter and much less sticks to its working surface, since the front cutting face cuts the soil and shifts it to the sides with minimal friction losses of the soil on the coulter surface. The stand of the standard coulter is subjected to excessive pressure (resistance) of the soil when moving, this is manifested in the crushing and unloading of the soil in front of the coulter during his work, which leads to increased traction resistance.

Further studies conducted in the laboratory confirmed the dependencies obtained during modeling in the program FlowVision. The lowest coulter has a lower coulter with an angle of sharpening of the coulter rack $\alpha=30$ degrees. and the angle of the coulter rack $\beta=10$ degrees. $[2,3]$. According to the data obtained, reducing the angle of sharpening $\alpha$ of the coulter rack and increasing the angle of inclination $\beta$ of the coulter rack decreases the pulling resistance of the opener. Thus, as the angle of sharpening $\alpha$ of the coulter stand is reduced by every 10 degrees, the traction resistance decreases by approximately $10 \%$, as well as the angle of inclination $\beta$ of the coulter stand is increased by every 5 degrees.

Next, we examined the soil soil grading after the passage of the serial and proposed lap openers (Fig. 3). According to agrotechnical requirements, the soil grading after the passage of the coulter of the seeder should not exceed 5\%. The FlowVision program modeled the soil surface after the coulters pass.
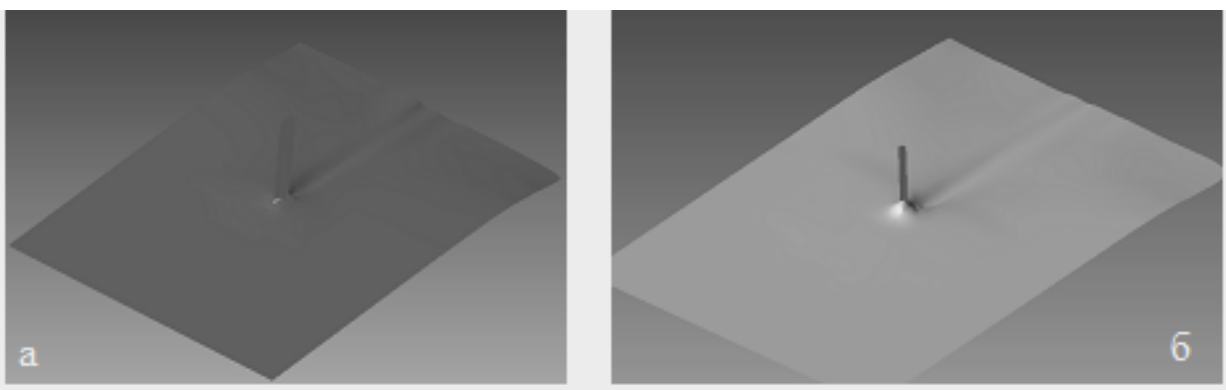

Fig. 3. Soil surface after the pass of coulters: a - proposed; $b$ - serial.

Analyzing the obtained images, we can say that the execution of the wedge coulter stand allows one to reduce the soil soil grazing after the coulter pass and to better grab the seeds with soil after sowing, without taking it beyond the furrow. While the standard coulter crushes the soil in front of him, removing the wet layer from the furrow, which negatively affects the height of the seed layer and the provision of moisture to the seeds, as the seeds are covered with dry soil due to the self-drying of the dry soil from the furrow walls.

Analysis of the response surfaces (Fig. 4) also shows that the proposed opener with the angle of sharpening of the opener rack $\alpha=30$ degrees. and the inclination angle of the coulter 
rack $\beta=10$ degrees allows to achieve the required agrotechnical parameters of soil codging after the coulter pass.

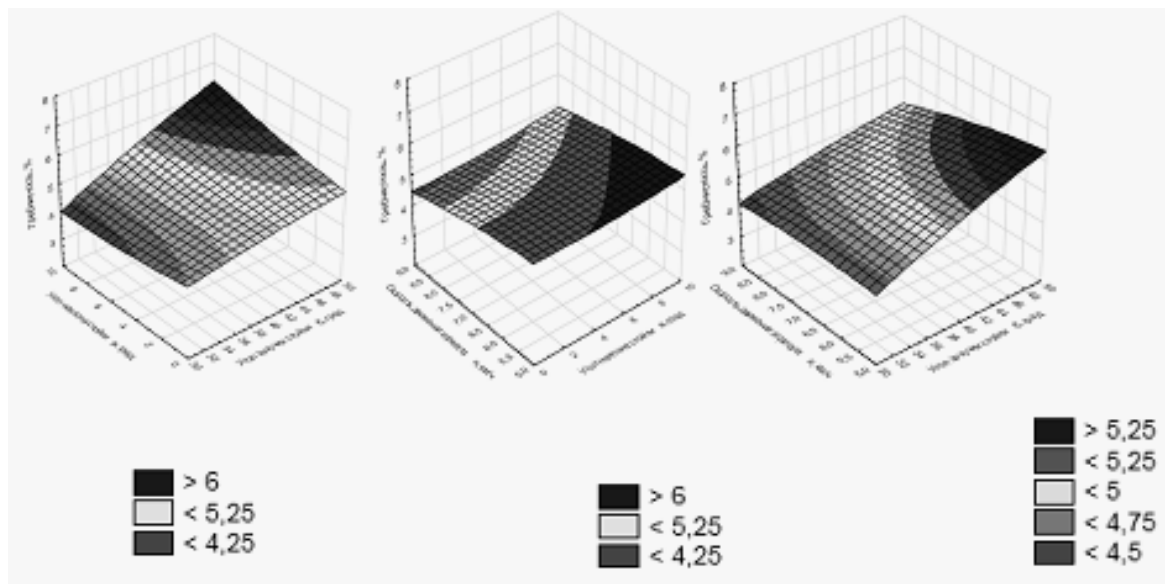

Fig. 4. Graphic representation of the surface response of soil crests after the passage of the proposed coulter from its design parameters: $\alpha$ - the angle of sharpening of the coulter rack, degrees; $\beta$ is the angle of inclination of the coulter rack, degrees; $v$ - speed of the unit, $\mathrm{km} / \mathrm{h}$.

The obtained data were confirmed by laboratory and production studies $[4,5,6]$.

\section{References}

1. Patent for invention № 2608014 Russian Federation, IPC A01C7 / 00. Vomer for different-level seeding of seeds and fertilizers / V.I. Kurdyumov, G.L. Tatars; Applicant and patent holder of Ulyanovsk State Agrarian University. - No. 2015137109; declare 08/31/2015; Publ. 01/11/2017; Bul No. 2

2. Kurdyumov V.I. New cultivator tool / V.I. Kurdyumov, E.S. Zykin, I.A. Sharonov // Rural mechanicizer. - 2012. - № 11. - p. 12.

3. Patent for utility model No. 150367 Russian Federation, IPC A01C7 / 00. Vomer for different-level seeding of seeds and fertilizers / V.I. Kurdyumov, E.S. Zykin, G.L. Tatars; Applicant and patent holder of Ulyanovsk State Agricultural Academy. - No. 2014115524/13; declare 04/17/2014; Publ. 02.20.2015; Bul No. 5

4. Kurdyumov, V.I. Experimental study of a ridge seeder equipped with combined coulters / V.I. Kurdyumov, E.S. Zykin, I.A. Sharonov, Biryukov I.V. // Bulletin of the Saratov State Agrarian University. N.I. Vavilova. - 2012. - № 11. - P.55-60.

5. Mudarisov, S.G. Modeling the process of interaction of working bodies with the soil / S.G. Mudarisov // Tractors and agricultural machines. - 2005. - № 7. - p. 27-30.

6. Kurdyumov, V.I. Development and research of machines for the mechanization of livestock and their working bodies / V.I. Kurdyumov. - Ulyanovsk, 2002. - 159 p. 